\title{
The Effect of Induction Chemotherapy Using Docetaxel, Cisplatin, and Fluorouracil on Survival in Locally Advanced Head and Neck Squamous Cell Carcinoma: A Meta-Analysis
}

\author{
Ryul Kim, MD \\ Seokyung Hahn, $\mathrm{PhD}^{2,3}$ \\ Junghoon Shin, MD' \\ Chan-Young Ock, MD' \\ Miso Kim, MD' \\ Bhumsuk Keam, MD, PhD1,4 \\ Tae Min Kim, MD, PhD',4 \\ Dong-Wan Kim, MD, PhD',4 \\ Dae Seog Heo, MD, PhD',4
}

${ }^{1}$ Department of Internal Medicine,

Seoul National University Hospital, Seoul,

${ }^{2}$ Medical Research Collaborating Center,

Seoul National University Hospital, Seoul,

${ }^{3}$ Department of Medicine,

Seoul National University

College of Medicine, Seoul,

${ }^{4}$ Cancer Research Institute,

Seoul National University

College of Medicine, Seoul, Korea

Correspondence: Bhumsuk Keam, MD, PhD

Department of Internal Medicine,

Seoul National University Hospital,

101 Daehak-ro, Jongno-gu, Seoul 03080, Korea

Tel: 82-2-2072-7215

Fax: 82-2-2072-7379

E-mail: bhumsuk@snu.ac.kr

Received September 21, 2015

Accepted November 6, 2015

Published Online November 17, 2015

${ }^{*}$ Ryul Kim and Seokyung Hahn contributed equally to this work.

\begin{abstract}
Purpose
The purpose of this study was to compare the survival of patients with locally advanced head and neck squamous cell carcinoma (LA-HNSCC) undergoing concurrent chemoradiotherapy (CRT) alone with that of patients undergoing induction chemotherapy (IC) using docetaxel, cisplatin, and 5-fluorouracil (TPF) followed by CRT.
\end{abstract}

\section{Materials and Methods}

A search of the PubMed, EMBASE, and Cochrane Library databases was performed in April 2015 and abstracts from the American Society of Clinical Oncology meetings (2008-2014) were reviewed. Summaries of the results were pooled using a fixed-effect model, and the risk of bias was evaluated using the Cochrane tool.

\section{Results}

A total of six relevant trials comprising 1,280 patients were identified. There was no statistically significant overall survival (OS) advantage for TPF prior to CRT (TPF/CRT) over CRT alone (hazard ratio [HR] 0.92; 95\% confidence interval [Cl], 0.79 to 1.09; $p=0.339$ ). Progression-free survival (PFS) was significantly longer in the TPF/CRT arms (HR, 0.82; 95\% $\mathrm{Cl}, 0.70$ to $0.95 ; \mathrm{p}=0.009$ ). Patients with non-oropharyngeal LA-HNSCC obtained the greatest OS and PFS benefits from TPF (HR, $0.68 ; 95 \% \mathrm{Cl}, 0.47$ to 0.99 ; $p=0.043$ and $\mathrm{HR}, 0.67$; $95 \% \mathrm{Cl}, 0.48$ to $0.94 ; p=0.022$, respectively). The complete response rate was significantly increased (risk ratio [RR], $1.34 ; 95 \% \mathrm{Cl}, 1.14$ to $1.56 ; p<0.001$ ), and the distant metastasis rate tended to decrease (RR, $0.65 ; 95 \% \mathrm{Cl}, 0.40$ to $1.04 ; \mathrm{p}=0.071)$ in the TPF/CRT arms.

\section{Conclusion}

IC with TPF followed by CRT is not superior to CRT alone for OS. However, PFS and the complete response rate were significantly improved in the TPF/CRT arms. TPF/CRT for patients with nonoropharyngeal LA-HNSCC provided clear survival advantages.

\section{Introduction}

Most patients with head and neck squamous cell carcinoma (HNSCC) present with locally or locoregionally advanced disease at diagnosis. Platinum-based concurrent chemoradiotherapy (CRT) has become a popular approach
Key words

Head and neck neoplasms, Induction chemotherapy, Chemoradiotherapy, Review, Meta-analysis 
Therefore, the use of systemic chemotherapy before definitive CRT, so-called induction chemotherapy (IC), has been theoretically attractive, and has been shown to reduce the incidence of distant metastasis and to support organ preservation $[3,4]$. Based on phase III studies that have established its superiority over cisplatin and 5-fluorouracil (PF) for response rate and survival, a regimen of docetaxel, cisplatin, and 5-fluorouracil (TPF) has emerged as the standard IC regimen [5-7]. In a recent meta-analysis of studies of IC regimens, overall survival (OS) provided by TPF was superior to that provided by PF [8]. However, whether or not the addition of TPF prior to CRT (TPF/CRT) will lead to further improvement in survival compared with CRT alone has not yet been proven.

A few randomized controlled trials have been conducted to address the efficacy of TPF/CRT over CRT alone for patients with LA-HNSCC, however they reported conflicting results. Three randomized phase III studies failed to prove that TPF/CRT provided improvement in OS compared with CRT alone [9-11]. However, these studies had low statistical power for detecting survival differences, because of slow accrual rates and premature study termination [12]. Subsequent to these studies, results of a randomized phase III trial of the largest number of patients were presented at the 2014 Annual Meeting of the American Society of Clinical Oncology. The results showed that IC with TPF followed by CRT was superior to CRT alone for complete response rate (CRR), progression-free survival (PFS), and OS [13]. In contrast, a recently published randomized phase II study and a metaanalysis failed to show any advantage of TPF/CRT [14,15].

The aims of our meta-analysis were to assess the question of whether or not TPF/CRT for patients with LA-HNSCC favorably impacts survival compared with CRT alone, and to identify patients who would most benefit from TPF/CRT.

\section{Materials and Methods}

\section{Inclusion criteria of studies}

All prospective clinical trials that compared the outcomes of TPF/CRT with those of CRT alone for patients with LA-HNSCC were considered eligible for inclusion in this meta-analysis. The study participants were patients with previously untreated, non-metastatic, histologically proven stage III or IV HNSCC who had adequate organ and marrow function. Patients were randomly assigned to receive either CRT alone (CRT arm) or induction TPF followed by CRT (TPF/CRT arm). Studies regarding IC other than TPF, and studies not published in English were excluded. In the case of a multi-arm study, only the TPF/CRT arm was selected as a comparator arm.

\section{Literature search strategy}

The initial literature search was conducted through PubMed, EMBASE, and the Cochrane Library. The following trial databases were also searched for ongoing and unpublished trials: the MetaRegister of controlled clinical trials (http://www.controlled-trials.com/) and the National Institutes of Health Clinical Trials Registry (http://clinicaltrials. gov/). In addition, we performed an individual search of the abstract listings from the annual meetings of the American Society of Clinical Oncology (2008-2014) for identification of potentially relevant studies. The detailed search strategy is shown in Supplementary Table 1.

Two reviewers (R.K., J.S.) performed an independent assessment of all of the obtained abstracts for their eligibility according to the inclusion criteria. For abstracts that were inconclusive for eligibility, the entire article was thoroughly reviewed by two reviewers (R.K., J.S.). Each trial that fulfilled the inclusion criteria was assessed for methodological quality using the Cochrane Collaboration's tool [16]. All disagreements between reviewers were resolved by consensus.

\section{Data extraction}

The following items were extracted from the articles: name of the first author, title and phase of each trial, year of publication, study location, characteristics of the treatments used in each arm, number of patients, proportion of patients who failed to complete CRT in each treatment arm, proportion of oropharyngeal cancer, hazard ratio (HR) for OS and PFS with corresponding $95 \%$ confidence interval (CI), radiologic response rate, and rate of grade 3-4 adverse events (AEs).

To avoid errors in the data abstraction process, data were extracted from articles by two independent reviewers (R.K., J.S.) and their results were compared. All data were checked for internal consistency, and disagreements were resolved by discussion. When the outcome data could not be extracted from the primary literature, the information was requested from the corresponding author of the publication in question.

\section{Statistical analysis}

The primary outcome was OS, defined as the time from random assignment to death from any cause. Secondary outcomes were PFS, overall response rate (ORR) and CRR, distant metastasis rate (DMR), locoregional recurrence rate (LRR), risk of failure to complete CRT, and grade 3-4 AEs. PFS was defined as the time from random assignment to locoregional or distant failure, or death from any cause with- 


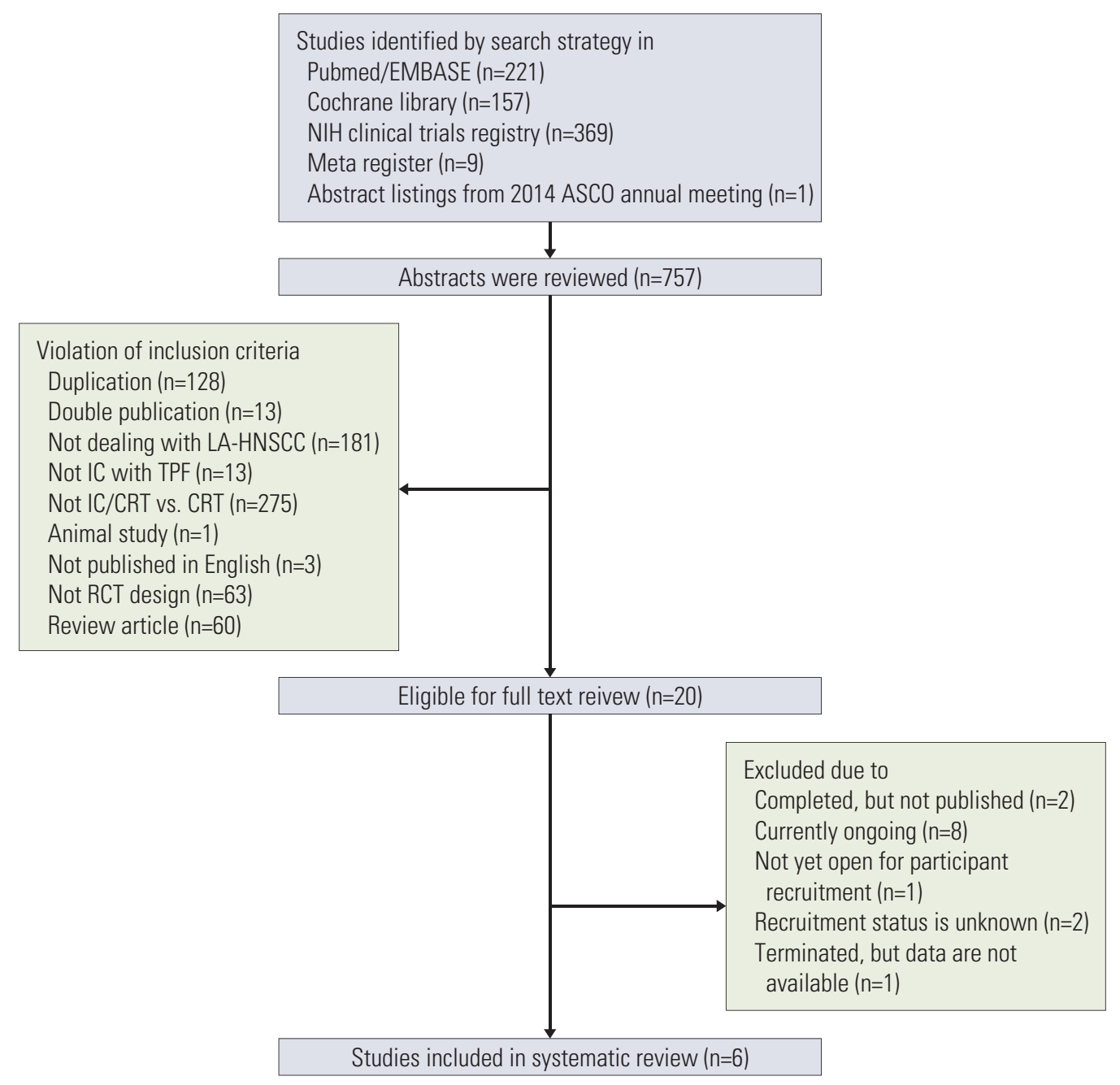

Fig. 1. Flow diagram for study review and inclusion. This search was performed in April 2015. ASCO, American Society of Clinical Oncology; NIH, National Institutes of Health; LA-HNSCC, locally-advanced head and neck squamous cell carcinoma; IC, induction chemotherapy; TPF, docetaxel, cisplatin, and 5-fluorouracil; CRT, concurrent chemoradiotherapy; RCT, randomized controlled trial.

out progression, whichever occurred first. ORR was defined as CRR and partial response rate after completion of CRT.

A fixed-effect model was used for calculation of pooled HRs or relative risks (RRs), 95\% CIs, and p-values. Twosided p-values less than 0.05 were considered statistically significant. Statistical heterogeneity was assessed using a formal statistical test that used the chi-square test and $\mathrm{I}^{2}$ statistic $[17,18]$. Once statistically significant heterogeneity was determined, a random-effect model was applied to evaluate the consistency of the result. The Begg and Egger funnel plot method was used to assess the possibility of publication bias $[19,20]$. Statistical analyses were performed using STATA ver. 11 (StataCorp., College Station, TX).

\section{Results}

\section{Literature search}

As shown in Fig. 1, the search of electronic databases and meeting abstracts resulted in a total of 757 citations. The abstracts of all citations were examined for relevance to the inclusion criteria. For all of the abstracts not excluded based on the initial review, the entire article was reviewed in detail for inclusion. Based on this review process, six trials met the inclusion criteria (Table 1).

There were some small differences in the chemotherapeutic agents and protocols for radiotherapy fractionation, as 
Table 1. Characteristics of studies included in the meta-analysis

\begin{tabular}{|c|c|c|c|c|c|c|c|c|}
\hline Author & Phase & $\begin{array}{l}\text { Study } \\
\text { location }\end{array}$ & $\begin{array}{l}\text { Primary } \\
\text { outcome }\end{array}$ & $\begin{array}{l}\text { Characteristics of } \\
\text { treatment in each arm }\end{array}$ & $\begin{array}{l}\text { Median } \\
\text { follow-up } \\
\text { period (mo) }\end{array}$ & Arm & $\begin{array}{c}\text { No. of } \\
\text { patients }\end{array}$ & $\begin{array}{l}\text { Oropharyngeal } \\
\text { cancer }(\%)\end{array}$ \\
\hline $\begin{array}{l}\text { Haddad } \\
\text { et al. } \\
(2013)[10]\end{array}$ & III & United States & OS & $\begin{array}{l}\text { CRT with cisplatin } \\
\mathrm{TPF} \times 3 \rightarrow \text { CRT with } \\
\text { docetaxel or carboplatin }\end{array}$ & 49 & $\begin{array}{c}\text { CRT } \\
\mathrm{TPF} / \mathrm{CRT}\end{array}$ & $\begin{array}{l}75 \\
80\end{array}$ & $\begin{array}{l}55.0 \\
56.0\end{array}$ \\
\hline $\begin{array}{l}\text { Cohen } \\
\text { et al. } \\
(2014)[9]\end{array}$ & III & $\begin{array}{l}\text { Croatia, France, } \\
\text { Russia, Spain, } \\
\text { United States }\end{array}$ & OS & $\begin{array}{l}\text { CRT with DFHX } \\
\text { TPF } \times 2 \rightarrow \text { CRT with } \\
\text { DFHX }\end{array}$ & $\mathrm{N} / \mathrm{A}$ & $\begin{array}{c}\text { CRT } \\
\mathrm{TPF} / \mathrm{CRT}\end{array}$ & $\begin{array}{l}135 \\
138\end{array}$ & $\begin{array}{l}55.6 \\
61.3\end{array}$ \\
\hline $\begin{array}{l}\text { Paccagnella } \\
\text { et al. } \\
(2010)[22]\end{array}$ & II & Italy & $\begin{array}{l}\text { Radiologic } \\
\text { CR rate }\end{array}$ & $\begin{array}{l}\text { CRT with cisplatin } / 5-\mathrm{FU} \\
\mathrm{TPF} \times 3 \rightarrow \mathrm{CRT} \text { with } \\
\text { cisplatin } / 5-\mathrm{FU}\end{array}$ & 42 & $\begin{array}{c}\text { CRT } \\
\text { TPF / CRT }\end{array}$ & $\begin{array}{l}51 \\
50\end{array}$ & $\begin{array}{l}51.0 \\
54.0\end{array}$ \\
\hline $\begin{array}{l}\text { Hitt et al. } \\
\text { (2014) [11] }\end{array}$ & III & Spain & $\begin{array}{l}\text { PFS } \\
\text { TTF }\end{array}$ & $\begin{array}{l}\text { CRT with cisplatin } \\
\text { TPF } \times 3 \rightarrow \text { CRT with } \\
\text { cisplatin }\end{array}$ & 24 & $\begin{array}{c}\text { CRT } \\
\mathrm{TPF} / \mathrm{CRT}\end{array}$ & $\begin{array}{l}128 \\
155\end{array}$ & $\begin{array}{l}42.2 \\
42.6\end{array}$ \\
\hline $\begin{array}{l}\text { Ghi et al. } \\
\text { (2014) [13] }\end{array}$ & III & Italy & OS & $\begin{array}{l}\text { CRT with cisplatin } \\
\text { /5-FU or cetuximab } \\
\text { TPF } \times 3 \rightarrow \text { CRT with cispatin } \\
\text { /5-FU or cetuximab }\end{array}$ & n & $\begin{array}{c}\text { CRT } \\
\mathrm{TPF} / \mathrm{CRT}\end{array}$ & $\begin{array}{l}207 \\
208\end{array}$ & $\begin{array}{l}56.0 \\
57.0\end{array}$ \\
\hline $\begin{array}{l}\text { Takacsi } \\
\text {-Nagy et al. } \\
(2015) \text { [15] }\end{array}$ & II & Hungary & $\begin{array}{l}\text { Radiologic } \\
\text { response rate }\end{array}$ & $\begin{array}{l}\text { CRT with cisplatin } \\
\text { TPF } \times 2 \rightarrow \text { CRT with } \\
\text { cisplatin }\end{array}$ & 63 & $\begin{array}{c}\text { CRT } \\
\mathrm{TPF} / \mathrm{CRT}\end{array}$ & $\begin{array}{l}33 \\
30\end{array}$ & $\begin{array}{l}52.0 \\
61.0\end{array}$ \\
\hline
\end{tabular}

OS, overall survival; CRT, concurrent chemoradiotherapy; TPF, docetaxel, cisplatin, and 5-fluorouracil; DFHX, docetaxel+ hydroxyurea+fluorouracil; N/A, not available; CR, complete response; 5-FU, 5-fluorouracil; PFS, progression-free survival; TTF, time-to-failure.

well as in the dosage and TPF schedules (Supplementary Table 2). The trial conducted by Hitt et al. [11] included an additional treatment arm, in which patients received IC with PF followed by CRT. As PF is not considered a standard IC regimen, the results of the $\mathrm{PF}$ arm were not included in this meta-analysis. The trial conducted by Ghi et al. [13] has not yet been formally published. Most studies stratified patients according to the primary tumor site, except for one trial conducted by Takacsi-Nagy et al. [15]. In most studies response evaluations were assessed according to the Response Evaluation Criteria in Solid Tumors (RECIST) [21], except one trial conducted by Haddad et al. [10] which did not specify the response evaluation criteria used.

\section{Survival analyses}

The six studies included a total of 1,280 individual patients, 651 of whom received IC using TPF followed by CRT, and 629 patients received CRT alone. The HRs of OS, PFS and its 95\% CIs were extracted from four of six studies [9-11,13], or calculated using other available statistical information by two independent reviewers (R.K., J.S.) in the trial conducted by Paccagnella et al. [22]. Data from the study conducted by Takacsi-Nagy et al. [15] were requested and provided from the corresponding author of the original study.

For a total of 1,280 patients, the pooled HR of OS and PFS were 0.92 (95\% CI, 0.79 to $1.09 ; \mathrm{p}=0.339)$ and $0.82(95 \% \mathrm{CI}$, 0.70 to $0.95 ; p=0.009$ ), respectively (Fig. 2 ). The heterogeneity was not statistically significant by chi-square or $\mathrm{I}^{2}$ testing for OS $\left(\mathrm{X}^{2}=7.44, \mathrm{df}=5[\mathrm{p}=0.190] ; \mathrm{I}^{2}=32.8 \%\right)$, and PFS $\left(\mathrm{X}^{2}=3.84, \mathrm{df}=5\right.$ $\left.[\mathrm{p}=0.573] ; \mathrm{I}^{2}=0.0 \%\right)$.

\section{Subgroup analyses}

Subgroup analyses were performed to determine the survival outcomes according to primary tumor site: oropharyneal and non-oropharyngeal LA-HNSCC. The survival data for the subgroup analysis were extractable from two out of 6 trials [10,13], comprising a total of 560 patients.

There was no statistically significant improvement of OS and PFS with TPF/CRT followed by CRT for oropharyngeal LA-HNSCC patients. The corresponding HRs were 0.89 (95\% CI, 0.62 to $1.28 ; \mathrm{p}=0.527$ ) for OS, and 0.89 ( $95 \% \mathrm{CI}, 0.64$ to 1.24 ; $\mathrm{p}=0.504$ ) for PFS (Fig. 3). In contrast, non-oropharyngeal LAHNSCC patients showed statistically significant improvement in OS and PFS (HR, $0.68 ; 95 \% \mathrm{CI}, 0.47$ to $0.99 ; \mathrm{p}=0.043$ and $\mathrm{HR}, 0.67 ; 95 \% \mathrm{CI}, 0.48$ to $0.94 ; \mathrm{p}=0.022$, respectively). 


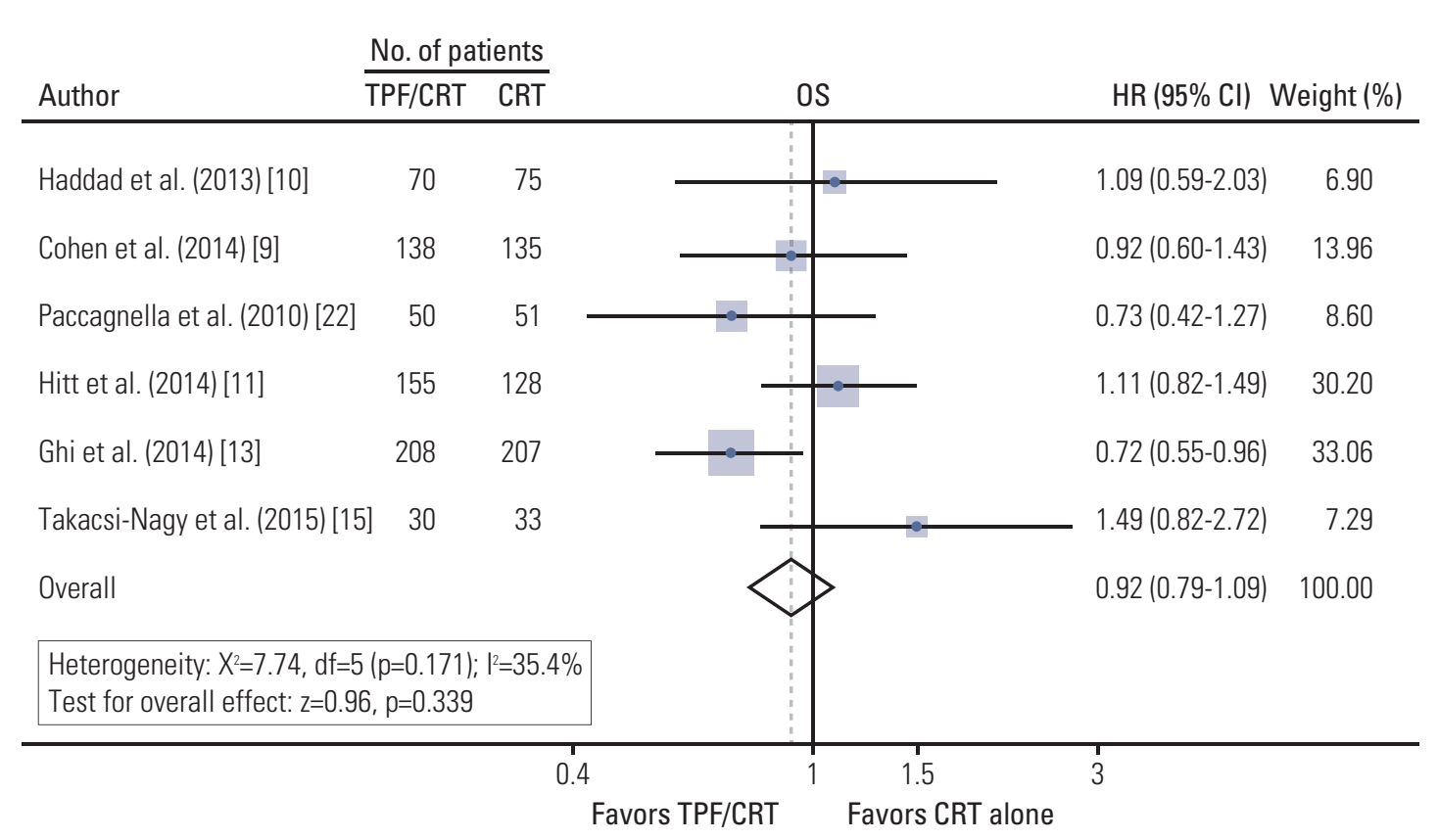

A

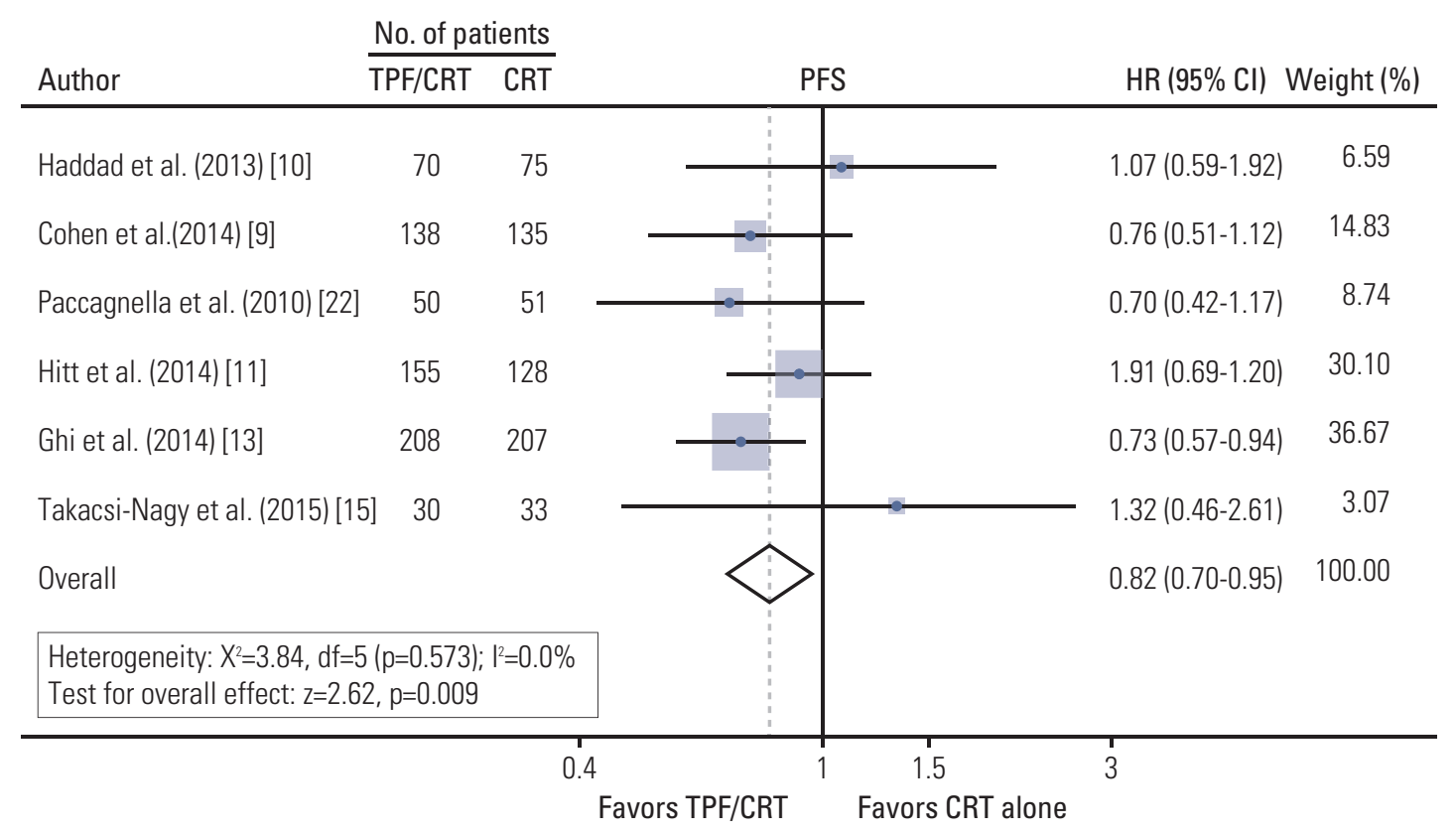

Fig. 2. Survival outcomes from the six randomized controlled trials comparing TPF/CRT with CRT alone. (A) Forest plot of OS. (B) Forest plot of PFS. TPF, docetaxel, cisplatin, and 5-fluorouracil; CRT, concurrent chemoradiotherapy; OS, overall survival; HR, hazard ratio; CI, confidence interval; df, degrees of freedom; PFS, progression-free survival. 


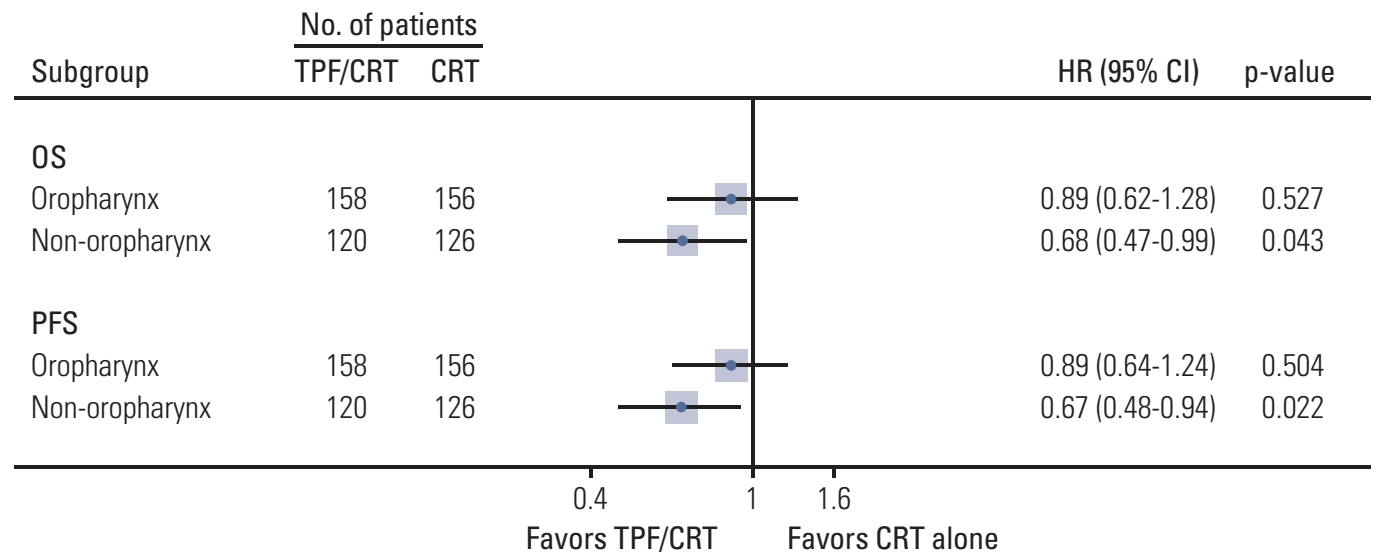

Fig. 3. Subgroup analysis for OS and PFS according to the primary tumor location. TPF, docetaxel, cisplatin, and 5-fluorouracil; CRT, concurrent chemoradiotherapy; HR, hazard ratio; CI, confidence interval; OS, overall survival; PFS, progression-free survival.

\section{Response rates}

Data for ORR were extractable from five $[9,11,13,15,22]$ of six trials, and comprised 991 patients (Fig. 4A). The trial conducted by Haddad et al. [10] did not report data for response rate. An overall response was observed in 439 of 499 patients in the TPF/CRT arms, and 409 of 492 patients in the CRT arms, resulting in a RR of 0.99 (95\% CI, 0.94 to $1.05 ; \mathrm{p}=0.858$ ). Heterogeneity was not statistically significant $\left(\mathrm{X}^{2}=1.71, \mathrm{df}=4\right.$ $\left.[\mathrm{p}=0.780] ; \mathrm{I}^{2}=0.0 \%\right)$. These data do not support a significant overall response advantage for the patients receiving TPF/CRT instead of CRT. Complete response was observed in 223 of 499 patients in the TPF / CRT arms, and 162 of 492 patients in the CRT arms (Fig. 4B), resulting in a RR of 1.34 (95\% CI, 1.14 to 1.56; $\mathrm{p}<0.001$ ). Despite statistically significant heterogeneity $\left(X^{2}=9.68, \mathrm{df}=4[\mathrm{p}=0.046] ; \mathrm{I}^{2}=58.7 \%\right)$, the beneficial effect of TPF/CRT in CRR was consistent in the same analysis performed using a random-effect model (RR, $1.30 ; 95 \% \mathrm{CI}, 1.01$ to $1.67 ; \mathrm{p}=0.046$ ).

\section{Relapse rates}

Data on DMR and LRR were available from two of 6 trials, comprising 418 patients $[9,11]$. Among the 208 patients in the TPF / CRT arms, there were 24 distant metastases, and among the 210 patients in the CRT arm, 37 distant metastases, resulting in a RR of 0.65 (95\% CI, 0.40 to 1.04; $\mathrm{p}=0.071$ ). Among 208 patients in the TPF/CRT arms, 25 locoregional events occurred, and among the 210 patients in the CRT arms, 28 events, resulting in a RR of 0.91 (95\% CI, 0.55 to 1.50; $\mathrm{p}=0.704$ ).

\section{Toxicity profiles}

The hematologic and nonhematologic AEs were assessed during CRT periods in five of six trials (Supplementary Fig. S1) $[9,11,13,15,22]$. The trial conducted by Haddad et al. [10] did not report toxicity profiles during the CRT period, instead they reported toxicity profiles for the entire period (both the IC and CRT periods) of treatment. Patients undergoing TPF / CRT had a higher risk of developing grade 3-4 neutropenia compared with those undergoing CRT alone (RR, 1.75; 95\% CI, 1.20 to 2.56; $p=0.004$ ). Grade 3-4 anemia and thrombocytopenia were significantly increased in the TPF/CRT arms compared to the CRT arms, with RRs 1.95 (95\% CI, 1.02 to 3.75; $\mathrm{p}=0.045$ ) and 2.40 (95\% CI, 1.17 to 4.90; $\mathrm{p}=0.017$ ), respectively. Differences in the rates of grade 3-4 nonhematologic AEs in the two treatment arms were not statistically significant.

\section{Risk of failure to complete CRT}

Data on the proportion of patients who did not complete CRT among those who were assigned in each treatment arm were available from all included trials $[9-11,13,15,22]$. Of 651 patients in the TPF/CRT arms, 173 patients failed to complete CRT (Fig. 5). In the CRT arms to which 629 patients were assigned, 101 patients failed to complete CRT. The pooled RR was 1.63 (95\% CI, 1.32 to 2.02; $\mathrm{p}<0.001)$. The heterogeneity was not statistically significant by $\mathrm{X}^{2}$ and $\mathrm{I}^{2}$ testing $\left(\mathrm{X}^{2}=5.42, \mathrm{df}=5[\mathrm{p}=0.366] ; \mathrm{I}^{2}=7.8 \%\right)$. 


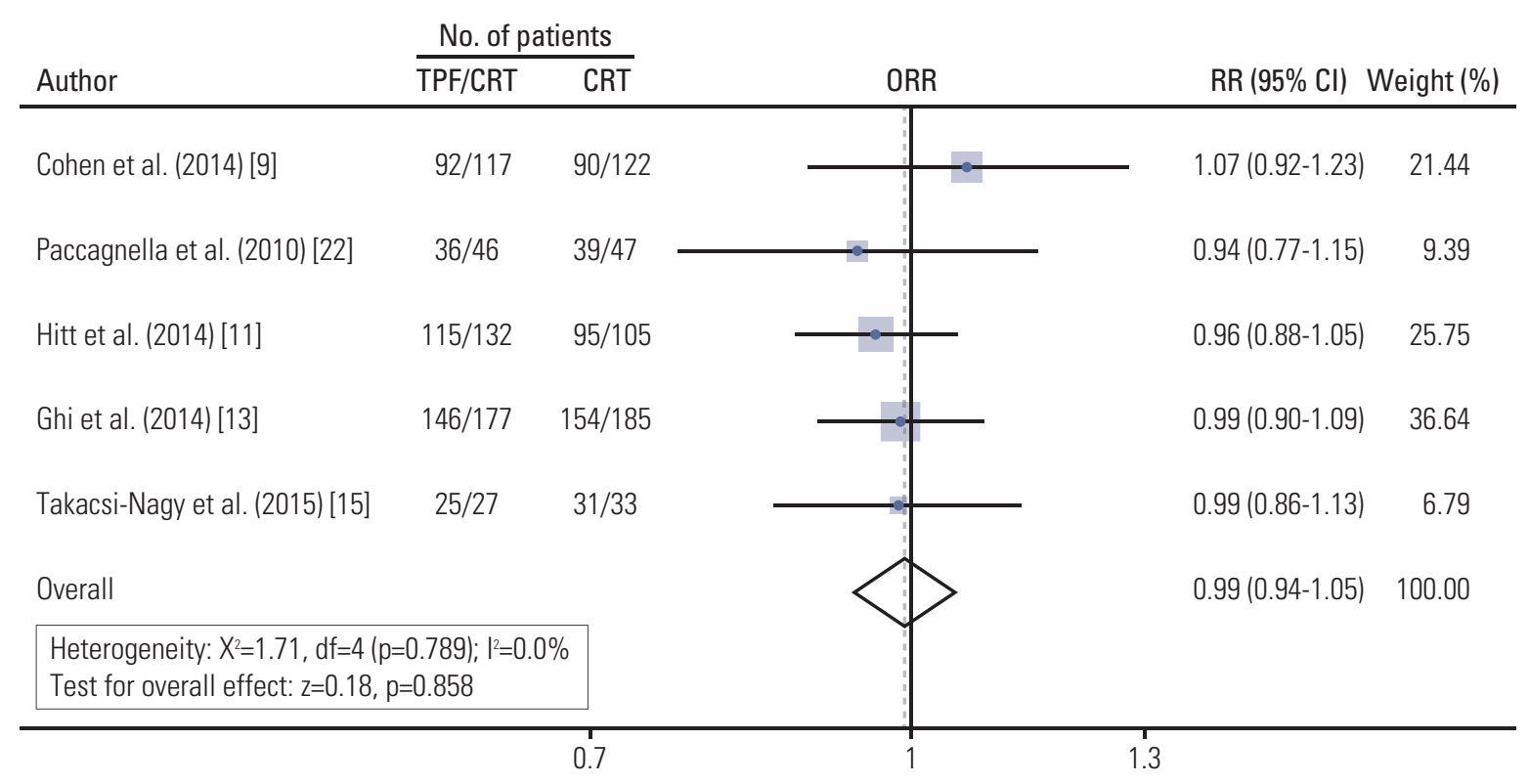

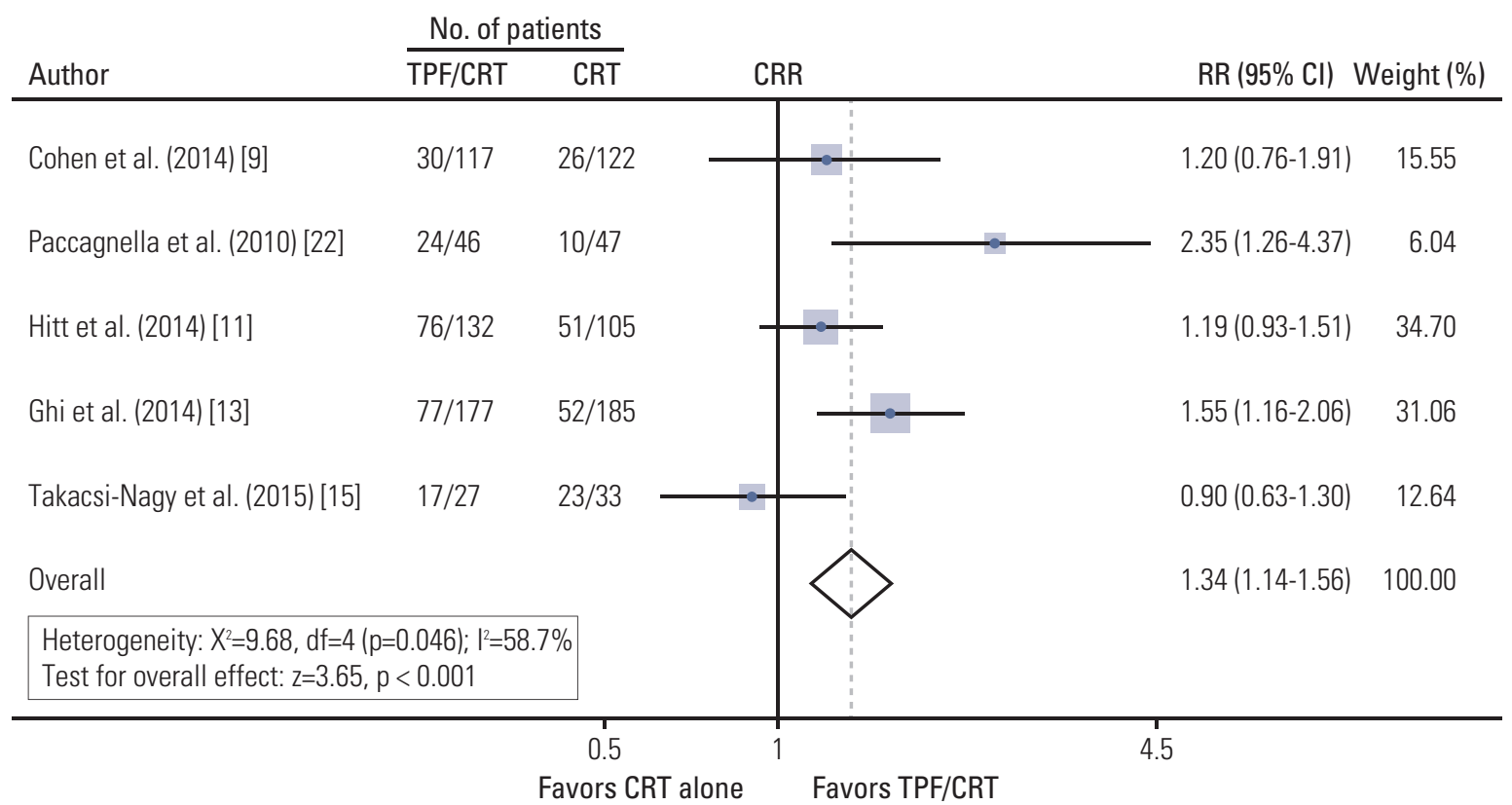

Fig. 4. Relative risks for ORR (A) and CRR (B) from the trials with available data. TPF, docetaxel, cisplatin, and 5-fluorouracil; $\mathrm{CRT}$, concurrent chemoradiotherapy; ORR, overall response rate; RR, relative risk; $\mathrm{CI}$, confidence interval; $\mathrm{df}$, degrees of freedom; CRR, complete response rate. 


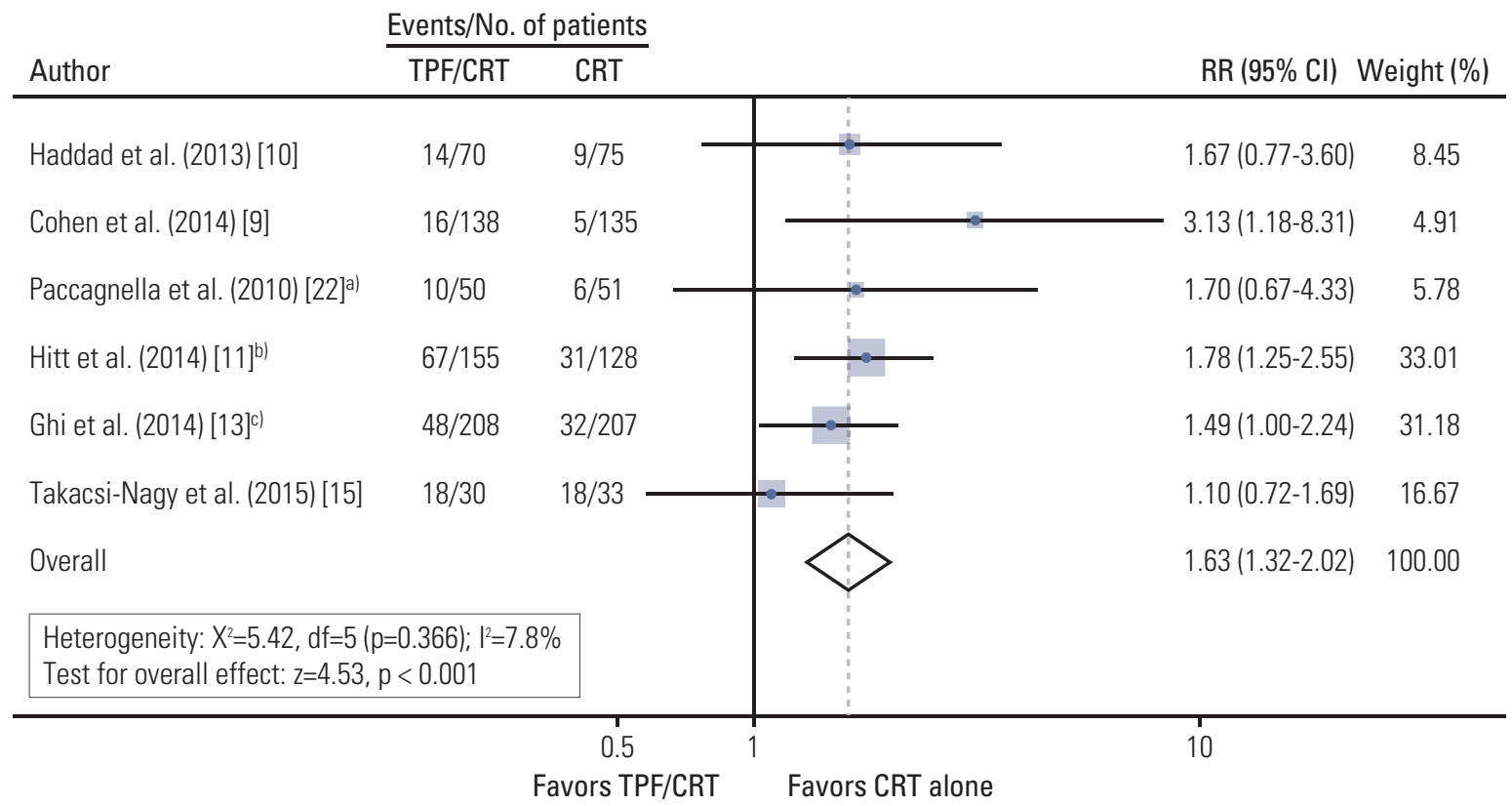

Fig. 5. Forest plot of relative risk for failure of completing chemoradiotherapy. TPF, docetaxel, cisplatin, and 5-fluorouracil; CRT, concurrent chemoradiotherapy; RR, relative risk; df, degrees of freedom; CI, confidence interval; PF, cisplatin and 5-fluorouracil. a)Patients who did not complete two cycles of PF during CRT were considered to have failed completion of CRT, ${ }^{\text {b) Among }} 155$ patients in the TPF/CRT arm, 28 patients discontinued before the third cycle of TPF and 19 patients discontinued after the third cycle of TPF but before CRT. In addition, 18 patients discontinued during the CRT period. Among 128 patients in the CRT arm, ten patients did not receive treatment, and 21 patients discontinued during the CRT period, c)Patients who did not complete two cycles of PF or cetuximab for 7 weeks were considered to have failed completion of CRT.

\section{Assessment of risk of bias}

The risk of bias in the six eligible studies was assessed using the risk assessment tool provided by the Cochrane Collaboration's tool (Supplementary Table 3) [16]. The adequacy of blinding was one of the most important aspects in the assessment of survival outcome. For all included studies $[9-11,13,15,22]$, the study participants and staff could not be blinded with regard to whether or not a participant had received IC. In addition, there was insufficient information about whether the treatment outcomes were evaluated by a third assessor who did not know the treatment group of the patient for all included studies. The trial conducted by Ghi et al. [13], which is the most recent and largest, has not yet been published. Therefore, the possibility of selective reporting could not be excluded.

\section{Assessment of publication bias}

Funnel plot analyses were performed (Supplementary
Fig. S2). However, because only six trials were analyzed in this meta-analysis the risk of publication bias in the included studies cannot be assessed.

\section{Discussion}

A regimen of TPF has emerged as the standard IC regimen for LA-HNSCC patients on the basis of phase 3 studies and a meta-analysis [5-8]. However, the question of whether the addition of TPF to CRT improves the results compared with administration of CRT alone has not yet been determined. In this meta-analysis of six trials enrolling a total of 1,280 patients with LA-HNSCC, IC with TPF followed by CRT was not superior to CRT alone for OS. However, patients undergoing TPF/CRT showed significantly better PFS. In particular, patients with non-oropharyngeal LA-HNSCC obtained the most benefit from TPF/CRT with statistically significant 
improvements in OS and PFS.

The outcome of LA-HNSCC has recently shown significant improvement, particularly for patients with oropharyngeal LA-HNSCC [23]. This improvement is due at least in part to the increasing incidence of human papillomavirus, which renders oropharyngeal LA-HNSCC more responsive to CRT [24]. Therefore, oropharyngeal LA-HNSCC patients who underwent CRT might have shown favorable prognosis regardless of the addition of IC with TPF/CRT. In contrast to oropharyneal LA-HNSCC, the outcome of non-oropharyngeal LA-HNSCC only trended toward improvement for decades. However, our results suggested that the outcome could be improved by IC with TPF/CRT.

Visual inspection of the forest plot for OS showed that the trial conducted by Takacsi-Nagy et al. [15] distinctly reported poorer OS compared with the other studies. This dismal outcome can be explained by the lower total dosages used for IC compared to the other trials (with the exception of the DeCIDE trial), and the relatively high incidence of T4 tumors [15]. In addition, patients were not stratified according to primary tumor site during randomization in this trial, resulting in a lower proportion of non-oropharyngeal LA-HNSCC patients in the TPF/CRT arm than in the CRT arm. Because our subgroup analysis found that patients with non-oropharyngeal LA-HNSCC obtained the most benefit from $\mathrm{TPF} / \mathrm{CRT}$, the discrepancy in types of patients in the two arms of their trial also contributed to the poorer OS of patients in the TPF/CRT arm.

Significant improvement was not observed in the ORR of patients receiving TPF/CRT, but was seen for their CRR, compared to patients who received CRT only. In addition, as previously reported $[3,4], \mathrm{TPF} / \mathrm{CRT}$ tended to reduce the DMR. However, patients treated with prior TPF were at significantly higher risk of failure to complete CRT compared to those treated with CRT alone. Finally, in the analysis of toxicity profiles, in comparison of AEs occurring during CRT in the TPF/CRT arms with those in the CRT arms, there was a significant increase in risk of grade 3-4 hematologic AEs, including anemia, thrombocytopenia, and neutropenia, as opposed to nonhematologic AEs. This study has several limitations. First, this meta-analysis did not include data on individual patients; therefore, it was not possible to adjust treatment effects according to primary site, differences of dose and schedule of TPF and CRT regimen, and patient variables such as infection with human papillomavirus. Second, only a small number of trials (2 of $6[10,13])$ were included in the subgroup analysis; therefore the statistical power of that analysis was low. Our requests for missing data for subgroup analysis from the investigators of each article were rejected or we received no response. Third, the trial conducted by Ghi et al. [13], which is the most recent and largest, has not yet been formally published. Therefore, their final results should be checked against the results in their abstract. Nevertheless, our study synthesized all of the current evidence, and, to the best of our knowledge, is the largest meta-analysis to date that addressed an important clinical issue, the effect of TPF followed by CRT on patients with LA-HNSCC. Unlike the prior meta-analysis conducted by Zhang et al. [14], our study was confined to the IC TPF regimen, which is regarded as the standard regimen, and our study included the most recent and largest trials [13,15].

\section{Conclusion}

With the best current available evidence, the results of this meta-analysis demonstrated that IC using TPF followed by CRT for patients with LA-HNSCC did not improve OS. However, PFS and CRR were significantly improved by TPF/CRT. Distinct survival advantages were observed in patients with non-oropharyngeal LA-HNSCC. Therefore, prudent selection of patients who could most benefit from TPF/CRT should lead to improved outcomes for LA-HNSCC patients. An extensive prospective randomized study, assessing the subpopulations of LA-HNSCC patients who would most benefit from TPF/CRT compared to CRT alone, is warranted.

\section{Electronic Supplementary Material}

Supplementary materials are available at Cancer Research and Treatment website (http://www.e-crt.org).

\section{Conflicts of Interest}

Conflict of interest relevant to this article was not reported. 


\section{References}

1. Pignon JP, Bourhis J, Domenge C, Designe L. Chemotherapy added to locoregional treatment for head and neck squamouscell carcinoma: three meta-analyses of updated individual data. MACH-NC Collaborative Group. Meta-Analysis of Chemotherapy on Head and Neck Cancer. Lancet. 2000;355: 949-55.

2. Haddad RI, Shin DM. Recent advances in head and neck cancer. N Engl J Med. 2008;359:1143-54.

3. Induction chemotherapy plus radiation compared with surgery plus radiation in patients with advanced laryngeal cancer. The Department of Veterans Affairs Laryngeal Cancer Study Group. N Engl J Med. 1991;324:1685-90.

4. Ferlay J, Parkin DM, Steliarova-Foucher E. Estimates of cancer incidence and mortality in Europe in 2008. Eur J Cancer. 2010; 46:765-81.

5. Hitt R, Lopez-Pousa A, Martinez-Trufero J, Escrig V, Carles J, Rizo A, et al. Phase III study comparing cisplatin plus fluorouracil to paclitaxel, cisplatin, and fluorouracil induction chemotherapy followed by chemoradiotherapy in locally advanced head and neck cancer. J Clin Oncol. 2005;23:8636-45.

6. Posner MR, Hershock DM, Blajman CR, Mickiewicz E, Winquist $\mathrm{E}$, Gorbounova V, et al. Cisplatin and fluorouracil alone or with docetaxel in head and neck cancer. N Engl J Med. 2007;357:1705-15.

7. Vermorken JB, Remenar E, van Herpen C, Gorlia T, Mesia R, Degardin $\mathrm{M}$, et al. Cisplatin, fluorouracil, and docetaxel in unresectable head and neck cancer. N Engl J Med. 2007;357: 1695-704

8. Blanchard P, Bourhis J, Lacas B, Posner MR, Vermorken JB, Hernandez JJ, et al. Taxane-cisplatin-fluorouracil as induction chemotherapy in locally advanced head and neck cancers: an individual patient data meta-analysis of the meta-analysis of chemotherapy in head and neck cancer group. J Clin Oncol. 2013;31:2854-60.

9. Cohen EE, Karrison TG, Kocherginsky M, Mueller J, Egan R, Huang $\mathrm{CH}$, et al. Phase III randomized trial of induction chemotherapy in patients with N2 or N3 locally advanced head and neck cancer. J Clin Oncol. 2014;32:2735-43.

10. Haddad R, O'Neill A, Rabinowits G, Tishler R, Khuri F, Adkins $\mathrm{D}$, et al. Induction chemotherapy followed by concurrent chemoradiotherapy (sequential chemoradiotherapy) versus concurrent chemoradiotherapy alone in locally advanced head and neck cancer (PARADIGM): a randomised phase 3 trial. Lancet Oncol. 2013;14:257-64.

11. Hitt R, Grau JJ, Lopez-Pousa A, Berrocal A, Garcia-Giron C, Irigoyen $\mathrm{A}$, et al. A randomized phase III trial comparing induction chemotherapy followed by chemoradiotherapy versus chemoradiotherapy alone as treatment of unresectable head and neck cancer. Ann Oncol. 2014;25:216-25.

12. Faivre S, Albert S, Raymond E. Induction chemotherapy challenges for head and neck cancer. Lancet Oncol. 2013;14:188-9.
13. Ghi MG, Paccagnella A, Ferrari D, Foa P, Cossu Rocca M, Verri E, et al. Concomitant chemoradiation (CRT) or cetuximab / RT (CET/RT) versus induction docetaxel/ cisplatin/5-fluorouracil (TPF) followed by CRT or CET/RT in patients with locally advanced squamous cell carcinoma of head and neck (LASCCHN). A randomized phase III factorial study (NCT01086826). J Clin Oncol. 2014;32(5S):Abstr 6004.

14. Zhang L, Jiang N, Shi Y, Li S, Wang P, Zhao Y. Induction chemotherapy with concurrent chemoradiotherapy versus concurrent chemoradiotherapy for locally advanced squamous cell carcinoma of head and neck: a meta-analysis. Sci Rep. 2015;5:10798.

15. Takacsi-Nagy Z, Hitre E, Remenar E, Oberna F, Polgar C, Major T, et al. Docetaxel, cisplatin and 5-fluorouracil induction chemotherapy followed by chemoradiotherapy or chemoradiotherapy alone in stage III-IV unresectable head and neck cancer: results of a randomized phase II study. Strahlenther Onkol. 2015;191:635-41.

16. Higgins JP, Green S. Cochrane Collaboration. Cochrane handbook for systematic reviews of interventions. West Sussex: John Wiley \& Sons; 2008.

17. DerSimonian R, Laird N. Meta-analysis in clinical trials. Control Clin Trials. 1986;7:177-88.

18. Higgins JP, Thompson SG, Deeks JJ, Altman DG. Measuring inconsistency in meta-analyses. BMJ. 2003;327:557-60.

19. Begg CB, Mazumdar M. Operating characteristics of a rank correlation test for publication bias. Biometrics. 1994;50:1088101.

20. Egger M, Davey Smith G, Schneider M, Minder C. Bias in meta-analysis detected by a simple, graphical test. BMJ. 1997; 315:629-34.

21. Therasse P, Arbuck SG, Eisenhauer EA, Wanders J, Kaplan RS, Rubinstein $\mathrm{L}$, et al. New guidelines to evaluate the response to treatment in solid tumors. European Organization for Research and Treatment of Cancer, National Cancer Institute of the United States, National Cancer Institute of Canada. J Natl Cancer Inst. 2000;92:205-16.

22. Paccagnella A, Ghi MG, Loreggian L, Buffoli A, Koussis H, Mione CA, et al. Concomitant chemoradiotherapy versus induction docetaxel, cisplatin and 5 fluorouracil (TPF) followed by concomitant chemoradiotherapy in locally advanced head and neck cancer: a phase II randomized study. Ann Oncol. 2010;21:1515-22.

23. Das LC, Karrison TG, Witt ME, Muller C, Stenson K, Blair EA, et al. Comparison of outcomes of locoregionally advanced oropharyngeal and non-oropharyngeal squamous cell carcinoma over two decades. Ann Oncol. 2015;26:198-205.

24. Ang KK, Harris J, Wheeler R, Weber R, Rosenthal DI, NguyenTan PF, et al. Human papillomavirus and survival of patients with oropharyngeal cancer. N Engl J Med. 2010;363:24-35. 